\title{
Long-term outcomes after coronary artery bypass grafting: Preoperative kidney function is prognostic
}

Michel B. Chonchol, MD, ${ }^{a}$ Victor Aboyans, MD, PhD, ${ }^{\mathrm{b}}$ Philippe Lacroix, MD, ${ }^{\mathrm{b}}$ Gerard Smits, PhD, ${ }^{\mathrm{c}}$ Tomas Berl, MD, and Marc Laskar, MD

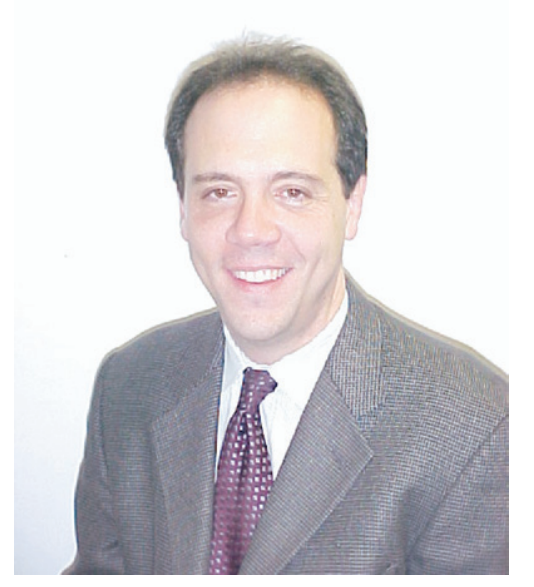

Dr Chonchol
From the University of Colorado Health Sciences Center, ${ }^{a}$ Division of Renal Diseases and Hypertension, Denver, Colo; the Department of Thoracic and Cardiovascular Surgery and Angiology, Dupuytren University Hospital, ${ }^{\mathrm{b}}$ Limoges, France; and CSC, Inc, Santa Barbara, Calif. ${ }^{c}$

Received for publication Nov 27, 2006; revisions received March 23, 2007; accepted for publication April 12, 2007.

Address for reprints: Michel B. Chonchol, MD, University of Colorado Health Sciences Center, Division of Renal Diseases and Hypertension; Box C-281, Denver, CO 80262 (E-mail: Michel.Chonchol@uchsc. edu).

J Thorac Cardiovasc Surg 2007;134:683-9

$0022-5223 / \$ 32.00$

Copyright $\odot 2007$ by The American Association for Thoracic Surgery

doi:10.1016/j.jtcvs.2007.04.029
Objective: End-stage renal disease is an independent predictor of mortality after coronary artery bypass grafting. Limited information exists, however, regarding the impact of chronic kidney disease on long-term outcome after bypass grafting. The purpose of this study was to assess the impact of kidney function on long-term outcomes in patients undergoing coronary artery bypass grafting.

Methods: We studied 931 consecutive patients undergoing coronary artery bypass grafting in a single center. Demographic and clinical data were collected preoperatively. Chronic kidney disease was defined preoperatively according to the Modification of Diet in Renal Disease equation as an estimated glomerular filtration rate less than $60 \mathrm{~mL} \cdot \mathrm{min}^{-1} \cdot 1.73 \mathrm{~m}^{-2}$. Multivariate Cox proportional hazard analyses were performed to determine the independent prognostic factors after bypass grafting. The primary outcome was a composite, combining death, acute coronary syndrome, stroke or transient ischemic attack, and coronary or peripheral revascularization during follow-up. Secondary outcomes were overall causes of death and cardiovascular death, acute coronary syndrome, and stroke or transient ischemic attack.

Results: One hundred fourteen $(12.2 \%)$ patients had preoperative chronic kidney disease (estimated glomerular filtration rate range, $20.5-59.8 \mathrm{~mL} \cdot \mathrm{min}^{-1} \cdot 1.73 \mathrm{~m}^{-2}$ ). After a mean follow-up of $3.1 \pm 1.4$ years (median, 3.3 years), chronic kidney disease was found to be an independent predictor of the composite outcome (hazard ratio and 95\% confidence interval, 1.46 [1.01-2.11]; $P=.0467)$ and overall death (hazard ratio and 95\% confidence interval, 1.89 [1.16-3.07]; $P=.0106$ ).

Conclusions: Beyond the perioperative period, preoperative moderate-to-severe chronic kidney disease is an independent long-term predictor of cardiovascular events and total mortality after coronary artery bypass grafting. Chronic kidney disease status should be incorporated into prediction models and clinical risk assessments.

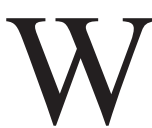

ith the aging of the population in Western countries, as well as the dramatic growth of reported rates of hypertension and diabetes, the prevalence of chronic kidney disease (CKD) and impaired kidney function is also increasing dramatically. ${ }^{1,2}$ These two latter conditions are frequently associated with widespread atherosclerotic disease, ${ }^{3}$ and as a consequence, coronary artery bypass grafting $(\mathrm{CABG})$ is increasingly considered for patients with definite CKD or kidney dysfunction. ${ }^{4}$

Several studies have reported a poor outcome in patients with end-stage renal disease $^{5,6}$ and kidney dysfunction after $\mathrm{CABG}^{7-9}$ but long-term data for the latter case are scarce. Additionally, most studies that have shown an association between preoperative kidney disease and a higher incidence of morbidity and mortality after CABG have concentrated on patients with elevated serum creatinine. ${ }^{6,10-13}$ How- 

Abbreviations and Acronyms
ACS = acute coronary syndrome
$\mathrm{CABG}=$ coronary artery bypass grafting
$\mathrm{CKD}=$ chronic kidney disease
CI = confidence interval
eGFR = estimated glomerular filtration rate
GFR = glomerular filtration rate
$\mathrm{HR}=$ hazard ratio
MDRD $=$ Modification of Diet in Renal Disease
PVD = peripheral vascular disease
TIA $=$ transient ischemic attack

ever, serum creatinine is not a sensitive marker, because its concentration is affected by factors other than glomerular filtration rate (GFR), such as creatinine generation, secretion, and extrarenal excretion. ${ }^{14}$ Recent published guidelines advise estimating GFR from prediction equations in patients with cardiovascular disease. ${ }^{15,16}$

There is limited information on the influence of moderateto-severe CKD on the long-term survival of patients undergoing CABG. ${ }^{17-19}$ The main objective of this study was to investigate the impact of preoperative CKD, defined as an estimated glomerular filtration rate (eGFR) of less than 60 $\mathrm{mL} \cdot \min ^{-1} \cdot 1.73 \mathrm{~m}^{-2}$ measured by the Modification of Diet in Renal Disease (MDRD) study equation on the longterm outcomes of cardiovascular events and total mortality after $\mathrm{CABG}$.

\section{Materials and Methods \\ Study Population and Measures}

The study cohort consisted of 931 consecutive patients who underwent CABG at the Dupuytren University Hospital, Limoges, France, between August 1998 and January 2002. All study participants signed an informed consent form before study entry. All preoperative and perioperative data, which included cardiovascular history and cardiovascular risk factors, were collected in a standard form. Patients were considered smokers when they were actively smoking or had stopped within 2 years before the operation. Patients were considered to have diabetes if they had a fasting blood glucose level at entry of more than $7.8 \mathrm{mmol} / \mathrm{L}$ or were taking oral hypoglycemic agents or insulin, or both. Those who had a blood pressure of $160 / 90 \mathrm{~mm} \mathrm{Hg}$ or higher measured twice before surgery or who were taking antihypertensive drugs for that purpose were considered to have hypertension. Hypercholesterolemia was defined by a fasting blood cholesterol level at entry of more than $240 \mathrm{mg} / \mathrm{dL}$ or by the need for lipid-lowering agents for that purpose. Supraventricular arrhythmia was defined by the presence of sustained atrial fibrillation or flutter on the preoperative electrocardiogram. Peripheral vascular disease (PVD) combined any report of clinical peripheral arterial disease (ie, an intermittent claudication and/or a history of vascular surgery for peripheral arterial disease) and any report of stroke or transitory ischemic attack (TIA) and/or any carotid surgery before enrolment. Patients undergoing emergency surgery (coronary angiography to surgery delay $<48$ hours) were excluded from the analysis. Patients with acute coronary syndrome (ACS) operated on beyond 48 hours and/or presenting hemodynamic instability were considered in an unstable cardiac status and were included in the study. Preoperative data included the number of bypasses performed, whether the revascularization was complete, the requirement of cardiopulmonary bypass or an off-pump surgery, and the performance of any combined procedure (ie, concomitant valvular or carotid surgery).

\section{Definition of CKD}

Preoperative serum creatinine was collected at admission. Serum creatinine was assessed by the Jaffé rate-balked and compensated method, using a kinetic colorimetric assay on the Roche/Hitachi Modular P analyzer (F. Hoffman-LaRoche Inc Ltd, Basel, Switzerland).

We estimated kidney function using a formula derived by the MDRD study group, as suggested by recent published guidelines. ${ }^{14,16}$ This equation expresses GFR in milliliters per minute per $1.73 \mathrm{~m}^{2}$ body surface area and is calculated as $186 \times$ (serum creatinine $\left.^{-1.154}\right) \times\left(\right.$ age $\left.^{-0.203}\right) \times 1.21$ (if black) $\times 0.742$ (if female), where serum creatinine is measured in milligrams per deciliter and age is in years. We defined CKD as an eGFR less than $60 \mathrm{~mL} \cdot \min ^{-1} \cdot 1.73 \mathrm{~m}^{-2} \cdot{ }^{14}$

\section{Outcomes}

The follow-up period corresponded to the interval from the day of CABG until March 1, 2004. Follow-up was performed by reviewing hospital charts, as well as by telephone contacts with patients' family physicians. The primary outcome was composite, corresponding to the occurrence of at least one of these events during the follow-up: death, nonfatal ACS corresponding to any type of myocardial infarction or unstable angina after surgery requiring admission to a coronary care unit, secondary coronary revascularization, nonfatal stroke or TIA requiring admission to a neurology department and defined by a neurologist during the hospital stay, and peripheral vascular surgery. Secondary outcomes studied were overall mortality and cardiovascular mortality.

\section{Statistical Analysis}

All statistical analyses were performed with SAS software version 8.2 (SAS Institute, Cary, NC). Summary statistics (mean and standard deviation for continuous variables and $\mathrm{N}$ and percent for discrete variables) were performed for all covariates, first for the overall sample and then separately by kidney function status. Comparisons were made between the two groups with $t$ tests or $\chi^{2}$ tests, as appropriate. Univariate Cox regression models were performed for each covariate for each primary or secondary outcome. The CKD status, as well as all other covariates being significant in univariate analyses, was entered into a multivariate model. Cox models were run successively with backward stepping, at each step removing the least significant term. The backward stepping continued until only significant terms remained in the model. KaplanMeier survival curves were produced for the composite, overall causes of death, and cardiovascular death outcome showing the survival curves for each CKD group. Nonlinearity between continuously measured eGFR and the outcome measures was explored by fitting restricted cubic splines, as well as by fitting a third- 
degree polynomial model. Log-rank statistics were calculated comparing the two groups.

\section{Results}

\section{Baseline Characteristics}

In this study population of 931 patients, 114 (12.2\%) had moderate-to-severe CKD as defined above (mean eGFR $46.6 \pm 10.7 \mathrm{~mL} \cdot \min ^{-1} \cdot 1.73 \mathrm{~m}^{-2}$, range: $20.5-59.8$ $\mathrm{mL} \cdot \min ^{-1} \cdot 1.73 \mathrm{~m}^{-2}$ ). These subjects were older, were more likely to be female, and were more likely to have a history of hypertension, diabetes, PVD, and New York Heart Association class III or IV than participants without CKD. A higher proportion of concomitant valvular surgery was noted in those with CKD (Table 1).

\section{Follow-up}

Patients were followed up for a mean of $3.1 \pm 1.4$ years (median, 3.3 years) after surgery.

During this period, $192(20.6 \%)$ patient results met the primary outcome. Ninety-four patients died, including 60 cases of cardiovascular death. Forty-two patients had ACS during follow-up, and 28 underwent secondary coronary revascularization. Thirty-three had a stroke or TIA, and 40 had peripheral vascular surgery.

Primary outcome. During the entire follow-up period, $37(32.5 \%)$ patients in the CKD group and $155(19 \%)$ in the group without CKD met the primary outcome $(P=.0009)$.

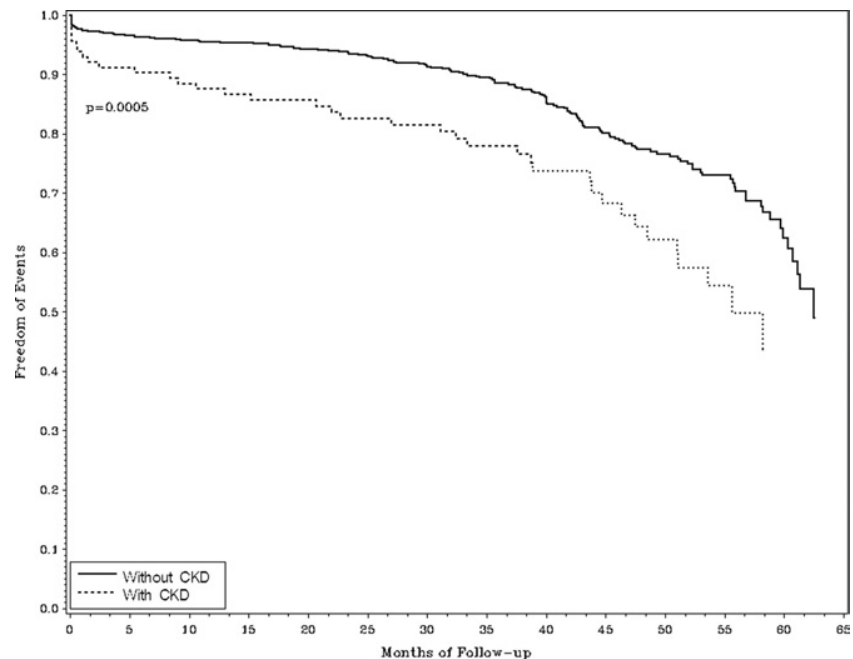

Figure 1. Kaplan-Meier estimates of probability of the composite end point after CABG by eGFR category. GFR is expressed in milliliters per minute per $1.73 \mathrm{~m}^{2}$. CKD, Chronic kidney disease; CABG, coronary artery bypass grafting; eGFR, estimated glomerular filtration rate; $\mathbf{G F R}$, glomerular filtration rate.

Figures 1, 2, and 3 show the composite, overall, and cardiovascular freedom from events curves according to the absence or presence of CKD, respectively. In univariate and multivariate analyses (Table 2), moderate-to-severe CKD

TABLE 1. Baseline characteristics in participants by baseline kidney function

\begin{tabular}{|c|c|c|c|c|}
\hline Characteristics & All $(\mathbf{n}=931)$ & $\begin{array}{c}\text { eGFR } \geq 60 \\
\left(\mathrm{~mL} \cdot \min \cdot 1.73 \mathrm{~m}^{-2}\right)(\mathrm{n}=817)\end{array}$ & $\begin{array}{c}\text { eGFR }<60 \\
\left(\mathrm{~mL} \cdot \min \cdot 1.73 \mathrm{~m}^{-2}\right)(\mathrm{n}=114)\end{array}$ & $P$ value \\
\hline Age (y) & $66.9 \pm 9.3$ & $66.5 \pm 9.0$ & $69.7 \pm 10.3$ & .0023 \\
\hline Male gender, n (\%) & $764(82.1)$ & $692(84.7)$ & $72(63.2)$ & $<.0001$ \\
\hline $\mathrm{BMI} \geq 30 \mathrm{~kg} / \mathrm{m}^{2}(\%)$ & $160(17.2)$ & $133(16.3)$ & $27(23.7)$ & .0503 \\
\hline Smoking, n (\%) & $278(29.9)$ & $248(30.4)$ & $30(26.3)$ & .3774 \\
\hline Hypercholesterolemia, n (\%) & $559(60.2)$ & $499(61.2)$ & $60(53.1)$ & .0980 \\
\hline Hypertension, n (\%) & $457(49.1)$ & $379(46.4)$ & $78(68.4)$ & $<.0001$ \\
\hline Diabetes, n (\%) & $246(26.5)$ & $198(24.3)$ & $48(42.1)$ & $<.0001$ \\
\hline Supraventricular arrhythmia, n (\%) & $77(8.3)$ & $63(7.7)$ & $14(12.3)$ & .0970 \\
\hline Ejection fraction (\%) & $63 \pm 14.8$ & $63.1 \pm 14.7$ & $62.2 \pm 15.6$ & .5691 \\
\hline NYHA III/IV, n (\%) & $151(16.2)$ & $124(15.2)$ & $27(23.7)$ & .021 \\
\hline Triple vessel disease, $\mathrm{n}(\%)$ & $604(64.9)$ & $530(64.9)$ & $74(64.9)$ & .9932 \\
\hline No. of bypasses & $3.01 \pm 0.98$ & $3.02 \pm 0.98$ & $2.93 \pm 0.99$ & .3426 \\
\hline LMCA stenosis $\geq 50 \%$, n ( $\%)$ & $151(16.2)$ & $126(15.4)$ & $25(21.9)$ & .0785 \\
\hline Redo surgery, n (\%) & $46(4.9)$ & $41(5.0)$ & $5(4.4)$ & .7704 \\
\hline Unstable cardiac status, n (\%) & $147(15.8)$ & $124(15.2)$ & $23(20.2)$ & .1722 \\
\hline On-pump surgery, n (\%) & $814(87.4)$ & $712(87.2)$ & $102(89.5)$ & .4829 \\
\hline Complete revascularization, n (\%) & $791(85 \%)$ & $696(85.2)$ & $95(83.3)$ & .6034 \\
\hline Concomitant valvular surgery, n (\%) & $145(15.6)$ & $118(14.4)$ & $27(27)$ & .0108 \\
\hline Concomitant carotid surgery, n (\%) & $27(2.9)$ & $23(2.8)$ & $4(3.51)$ & .6793 \\
\hline Peripheral vascular disease, $\mathrm{n}(\%)$ & $201(21.6)$ & $163(20)$ & $38(33)$ & .0011 \\
\hline $\mathrm{eGFR}\left(\mathrm{mL} \cdot \min ^{-1} \cdot 1.73 \mathrm{~m}^{-2}\right)$ & $75.5 \pm 15.4$ & $79.1 \pm 11.3$ & $46.6 \pm 10.7$ & $<.0001$ \\
\hline
\end{tabular}

Values presented with \pm are means \pm SD. BMI, Body mass index; eGFR, estimated glomerular filtration rate; $L M C A$, left main coronary artery; NYHA, New York Heart Association. 


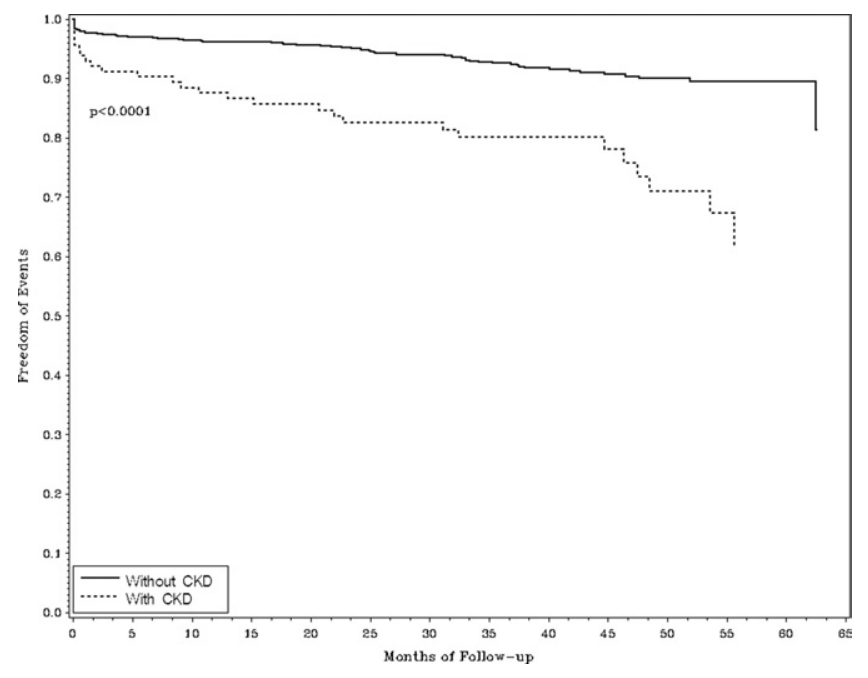

Figure 2. Kaplan-Meier estimates of probability of overall survival after CABG by eGFR category. GFR is expressed in milliliters per minute per $1.73 \mathrm{~m}^{2}$. Definitions of acronyms as in Figure 1.

was independently associated with the occurrence of the primary composite outcome during follow-up. The model was repeated, replacing the binary CKD variable by eGFR as a continuous variable. After multivariate adjustment, eGFR remained significantly associated with the primary outcome, with a hazard ratio (HR) at 1.11 (95\% confidence interval $[\mathrm{CI}] 1.01,1.22 ; P=.0396)$ per $10 \mathrm{~mL} \cdot \mathrm{min}^{-1}$. $1.73 \mathrm{~m}^{-2}$ decrease of eGFR (full model not shown). Other independent predictors of the primary outcome included increased age, preoperative supraventricular arrhythmia, New York Heart Association class III or IV, concomitant valvular surgery, presence of PVD, and unstable cardiac status. Furthermore, the relationship between eGFR and outcome appeared linear, since no additional information was provided with nonlinear models.

Secondary outcomes. During the follow-up period, participants with CKD also had higher rates of overall deaths $(23.7 \%$ vs $8.2 \% ; P<.0001)$ and cardiovascular deaths $(12.3 \%$ vs $5.6 \% ; P=.007)$ than patients without CKD. CKD was also a powerful predictor of overall mortality in univariate and multivariate analyses but was only shown to be a predictor of cardiovascular death in the univariate analysis (Table 3). The model was repeated with eGFR used as a continuous variable instead of CKD. After multivariate adjustment, the HR of overall death increased by 1.20 (95\% CI, $1.05,1.36 ; P=.0054)$ per $10 \mathrm{~mL} \cdot \min ^{-1} \cdot 1.73 \mathrm{~m}^{-2}$ decrease of eGFR. No significant association was observed between eGFR and cardiovascular death in the multivariate analysis (data not shown). Other independent predictors for both overall and cardiovascular mortality included female gender, an ejection fraction less than $40 \%$, unstable cardiac

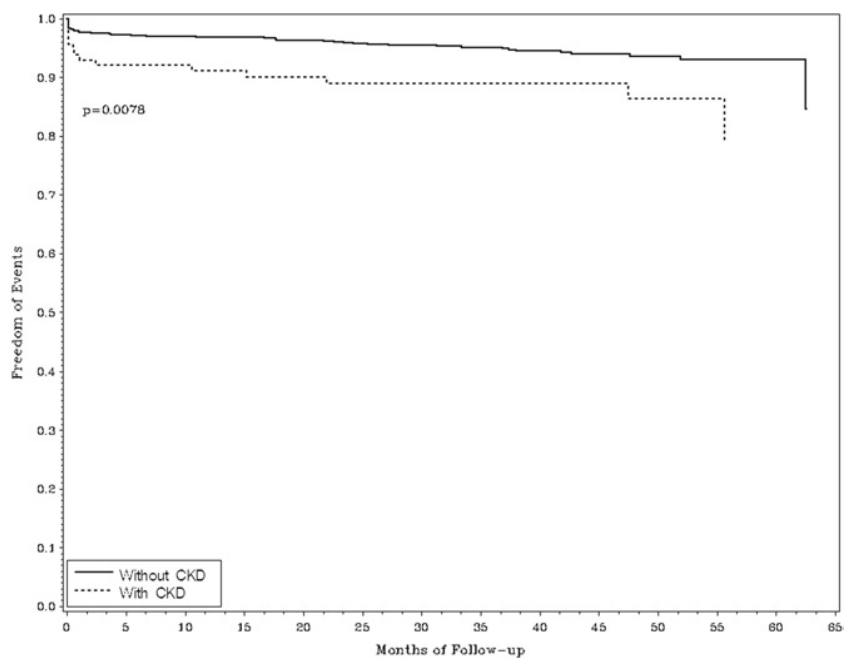

Figure 3. Kaplan-Meier estimates of probability of cardiovascular survival after CABG by eGFR category. GFR is expressed in milliliters per minute per $1.73 \mathrm{~m}^{2}$. Definitions of acronyms as in Figure 1.

status, concomitant valvular surgery, and PVD. In addition, fitting a cubic spline to eGFR revealed a sharp increase in the composite and overall-death outcome at an eGFR level of less than $60 \mathrm{~mL} \cdot \min ^{-1} \cdot 1.73 \mathrm{~m}^{-2}$ (Figure 4).

Postoperative (30-day) outcomes. During the initial postoperative 30 days of observation, only 28 patients met the primary outcome. Twenty-six patients died, 6 had ACS, 4 had a stroke or TIA, and only 1 patient underwent redux coronary revascularization. In univariate analyses, moderate-to-severe CKD was associated with the occurrence of the composite outcome $(\mathrm{HR}=2.42,95 \% \mathrm{CI}, 1.03-5.69 ; P=.0431)$ and overall death $(\mathrm{HR}=2.67,95 \% \mathrm{CI}, 1.22-6.35 ; P=.0263)$. When eGFR was used as a continuous variable, similar significant results were obtained for the composite outcome $(\mathrm{HR}=1.35,95 \% \mathrm{CI}, 1.10-1.67)$ and overall death $(\mathrm{HR}=$ $1.37,95 \%$ CI, 1.10-1.69). In multivariate analyses, CKD was not found to be significantly associated with any of the outcomes evaluated. In this cohort, the only significant predictors at 30 days for the composite outcome and overall death included male gender, New York Heart Association class III or $\mathrm{IV}$, and unstable cardiac status (data not shown).

\section{Discussion}

In this longitudinal study, moderate-to-severe preoperative CKD was found to be a significant predictive marker of subsequent events in patients after CABG. This prognostic value is independent of many usual prognostic comorbidities, which can be shared between coronary artery disease and CKD, including diabetes, hypertension, heart failure, or the presence of PVD. In this cohort, the $12 \%$ prevalence of $\mathrm{CKD}$ in patients undergoing $\mathrm{CABG}$ is relatively low, com- 
TABLE 2. Predictors of primary composite end point by Cox regression: Univariate and multivariate analyses

\begin{tabular}{|c|c|c|c|c|}
\hline \multirow[b]{2}{*}{ Characteristics } & \multicolumn{2}{|c|}{ Univariate } & \multicolumn{2}{|c|}{ Multivariate } \\
\hline & HR $(95 \%$ Cl) & $P$ value & HR $(95 \% \mathrm{CI})$ & $P$ value \\
\hline Age & $1.04(1.02-1.06)$ & .0001 & $1.02(1.00-1.04)$ & .0455 \\
\hline Male gender & $0.80(0.56-1.13)$ & .2068 & - & - \\
\hline $\mathrm{BMI} \geq 30 \mathrm{~kg} / \mathrm{m}^{2}$ & $1.00(0.69-1.45)$ & .9930 & - & - \\
\hline Smoking & $1.18(0.88-1.59)$ & .2720 & - & - \\
\hline Hypercholesterolemia & $0.82(0.62-1.09)$ & .1784 & - & - \\
\hline Hypertension & $1.02(0.77-1.35)$ & .9151 & - & - \\
\hline Diabetes & $1.06(0.77-1.46)$ & .7186 & - & - \\
\hline Supraventricular arrhythmia & $2.34(1.56-3.50)$ & .0000 & $1.54(1.00-2.35)$ & .0480 \\
\hline Chronic kidney disease & $1.88(1.31-2.69)$ & .0006 & $1.46(1.01-2.11)$ & .0467 \\
\hline Ejection fraction $\geq 40 \%$ & $0.58(0.36-0.94)$ & .0265 & - & - \\
\hline NYHA III/IV & $2.35(1.70-3.24)$ & .0000 & $1.55(1.07-2.25)$ & .0195 \\
\hline Triple vessel disease & $0.99(0.74-1.34)$ & .9744 & - & - \\
\hline Number of bypasses & $0.97(0.77-1.21)$ & .7556 & - & - \\
\hline LMCA stenosis $\geq 50 \%$ & $1.57(1.10-2.24)$ & .0120 & - & - \\
\hline Redo surgery & $1.05(0.58-1.88)$ & .8833 & - & - \\
\hline Unstable cardiac status & $1.77(1.25-2.49)$ & .0011 & $1.53(1.08-2.17)$ & .0174 \\
\hline On-pump surgery & $0.90(0.52-1.57)$ & .7054 & - & - \\
\hline Complete revascularization & $0.86(0.59-1.26)$ & .4438 & - & - \\
\hline Concomitant valvular surgery & $2.29(1.64-3.19)$ & .0000 & $1.69(1.15-2.47)$ & .0071 \\
\hline Concomitant carotid surgery & $1.42(0.73-2.78)$ & .3049 & - & - \\
\hline Peripheral vascular disease & $1.82(1.35-2.46)$ & .0001 & $1.65(1.21-2.25)$ & .0015 \\
\hline
\end{tabular}

$H R$, Hazard ratio; $C l$, confidence interval; BMI, body mass index; NYHA, New York Heart Association; LMCA, left main coronary artery.

pared with $21 \%$ to $37 \%$ reported elsewhere..$^{9,13,18,19}$ Nevertheless, CKD was shown to increase the risk for the primary composite outcome of death, nonfatal ACS, coronary revascularization, stroke and peripheral vascular surgery, as well as overall mortality alone, by $46 \%$ and $89 \%$, respectively.

Data on moderate-to-severe CKD defined by a more reliable estimate of kidney function (eGFR) and its prognostic value on a variety of long-term cardiovascular outcomes are scarce. ${ }^{9,18}$ In an analysis from The Society of Thoracic Surgeons National Cardiac Database, Cooper and associates $^{9}$ reviewed the case histories of 483,914 patients receiving isolated $\mathrm{CABG}$. The authors showed an association between eGFR and operative mortality and morbidities, but specific long-term cardiovascular end points were not evaluated. In a British study, ${ }^{18} 37 \%$ of patients undergoing CABG presented with an eGFR less than $60 \mathrm{~mL} \cdot \min ^{-1}$. $1.73 \mathrm{~m}^{-2}$, and eGFR was an independent predictor of shortand long-term mortality. The only outcome evaluated was overall mortality, and the median length of follow-up was 2.3 years. With a longer follow-up period of 3.3 years, our study is the first providing evidence of the additive predictive power of eGFR on a series of combined cardiovascular end point and overall mortality. ${ }^{19}$

Although we did not observe CKD to be an independent predictor of the short-term (30 days) postoperative outcome, most likely because of very few events that had accrued during this period, the interpretation of the survival curves after $\mathrm{CABG}$ in our cohort suggest that the highest risk of achieving the composite outcome and overall death in the group with CKD can be observed in the initial 12 months after surgery. After this period, the survival curves appeared to be parallel in CKD and no-CKD patients.

The National Kidney Foundation has recommended that GFR should be estimated from prediction equations that include serum creatinine concentration and some or all of the following variables: age, sex, race, and body size. The MDRD study and Cockcroft-Gault equations provide useful estimates of GFR in adults. ${ }^{14}$ We have chosen for our analysis to primarily define CKD on the basis of the MDRD study equation because it has been established to be more accurate in patients with moderate-to-severe kidney disease. ${ }^{16}$ Furthermore, an independent association has been established between reduced eGFR measure by the MDRD equation and the risk of death, cardiovascular events, and hospitalization in large, community-based populations. ${ }^{20}$ In addition, the science advisory from the American Heart Association Kidney and Cardiovascular Disease Council recently recommended that all patients with cardiovascular disease should be screened for evidence of kidney disease with the combined use of the MDRD equation to estimate GFR and a sensitive test to detect microalbuminuria. ${ }^{15}$

Studies in patients with cardiovascular disease have consistently shown that the level of kidney function is an independent risk factor for cardiovascular mortality. ${ }^{20-23}$ 
TABLE 3. Predictors of total and cardiovascular mortality by Cox regression: Univariate and multivariate analyses

\begin{tabular}{|c|c|c|c|c|c|c|c|c|}
\hline \multirow[b]{3}{*}{ Characteristics } & \multicolumn{4}{|c|}{ Overall mortality } & \multicolumn{4}{|c|}{ Cardiovascular mortality } \\
\hline & \multicolumn{2}{|c|}{ Univariate } & \multicolumn{2}{|c|}{ Multivariate } & \multicolumn{2}{|l|}{ Univariate } & \multicolumn{2}{|c|}{ Multivariate } \\
\hline & HR $(95 \% \mathrm{Cl})$ & $P$ value & HR (95\% Cl) & $P$ value & HR (95\% Cl) & $P$ value & HR $(95 \%$ Cl) & $P$ value \\
\hline Male gender & $0.48(0.31-0.75)$ & .0012 & $0.58(0.36-0.94)$ & .0257 & $0.44(0.25-0.76)$ & .0032 & $0.42(0.23-0.76)$ & .0041 \\
\hline $\mathrm{BMI} \geq 30 \mathrm{~kg} / \mathrm{m}^{2}$ & $1.09(0.65-1.83)$ & .7445 & - & - & $1.14(0.60-2.15)$ & .6862 & - & - \\
\hline Hypertension & $1.07(0.71-1.60)$ & .7524 & - & - & $1.25(0.75-2.08)$ & .3918 & - & - \\
\hline Diabetes & $1.25(0.80-1.93)$ & .3236 & - & - & $1.43(0.83-2.45)$ & .1953 & - & - \\
\hline Supraventricular arrhythmia & $2.32(1.33-4.03)$ & .0029 & - & - & $3.02(1.60-5.69)$ & .0007 & - & - \\
\hline CKD & $3.04(1.95-4.81)$ & .0000 & $1.89(1.16-3.07)$ & .0106 & $2.22(1.21-4.10)$ & .0096 & - & - \\
\hline $\mathrm{EF} \geq 40 \%$ & $0.44(0.24-0.81)$ & .0079 & $0.46(0.25-0.85)$ & .0139 & $0.32(0.16-0.63)$ & .0010 & $0.32(0.16-0.64)$ & .0014 \\
\hline NYHA III/IV & $2.49(1.59-3.90)$ & .0001 & - & - & $3.50(2.06-5.94)$ & .0000 & - & - \\
\hline Redo surgery & $1.18(0.51-2.70)$ & 6988 & - & - & $1.29(0.47-3.55)$ & .6271 & - & - \\
\hline Unstable cardiac status & $1.73(1.06-2.81)$ & .0280 & $1.80(1.08-3.01)$ & .0234 & $2.14(1.21-3.80)$ & .0093 & $2.64(1.44-4.84)$ & .0018 \\
\hline On-pump surgery & $2.36(0.86-6.44)$ & .0951 & - & - & $2.16(0.67-6.92)$ & .1967 & - & - \\
\hline Complete revascularization & $0.77(0.46-1.28)$ & .3105 & - & - & $0.93(0.47-1.85)$ & .8445 & - & - \\
\hline Concomitant valvular surgery & $3.19(2.07-4.93)$ & .0000 & $2.61(1.59-4.30)$ & .0002 & $4.29(2.54-7.25)$ & .0000 & $4.83(2.77-8.43)$ & $<.0001$ \\
\hline Concomitant carotid surgery & $1.40(0.51-3.81)$ & .5114 & - & - & $1.10(0.27-4.50)$ & .8989 & - & - \\
\hline PVD & $2.02(1.32-3.09)$ & .0012 & $1.89(1.20-2.97)$ & .0057 & $1.97(1.16-3.36)$ & .0124 & $1.99(1.13-3.54)$ & .0180 \\
\hline
\end{tabular}

$H R$, Hazard ratio; $C l$, confidence interval; $B M I$, body mass index; $C K D$, chronic kidney disease; $E F$, ejection fraction; $L M C A$, left main coronary artery; $N Y H A$, New York Heart Association; PVD, peripheral vascular disease.

This association has multiple explanations: (1) Excess comorbidities have been reported in patients with CKD, including volume expansion resulting from sodium retention, hypertension, and insulin resistance with impaired glucose

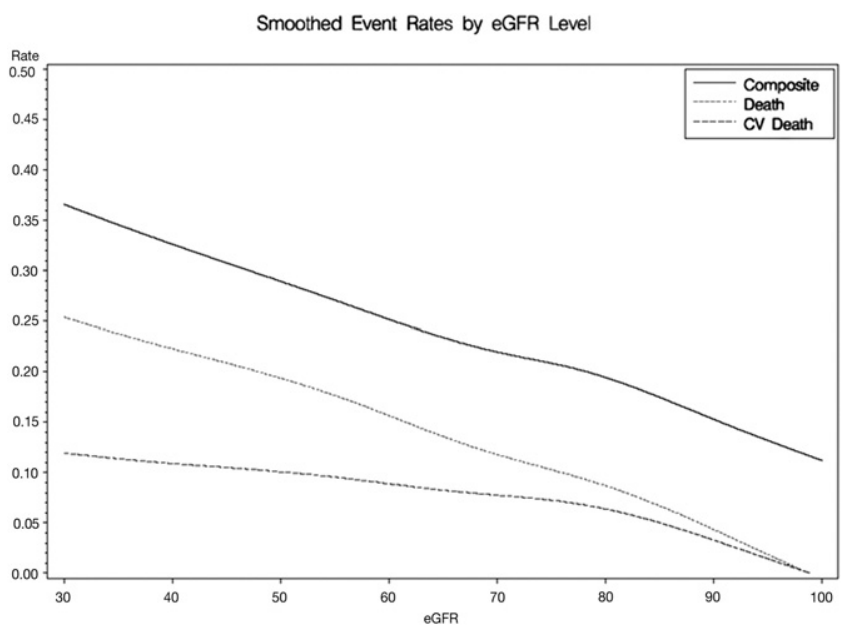

Figure 4. Cubic spline analysis for risk of outcome (composite, death, and cardiovascular [CV] death) with decreasing eGFR. GFR is expressed in milliliters per minute per $1.73 \mathrm{~m}^{2}$. eGFR, Estimated glomerular filtration rate; GFR, glomerular filtration rate. tolerance. ${ }^{24}$ (2) Abnormal vascular biology in CKD has been widely established; as renal function declines, a host of abnormalities develops, including increased oxidative stress, inflammation (eg, increased c-reactive protein), ${ }^{25,26}$ phosphate retention with medial vascular calcification, ${ }^{27}$ increased parathyroid hormone concentrations with myocardial calcification and dysfunction, ${ }^{28}$ and anemia and left ventricular hypertrophy, ${ }^{29}$ all of which could increase cardiovascular disease. ${ }^{23}$ Increased plasma homocysteine, fibrinogen, and uric acid are other cardiovascular risk factors that occur with CKD. ${ }^{23,24}$ (3) Numerous studies ${ }^{23,30}$ have linked the presence of CKD with underuse of key cardiovascular medications after CABG. (4) Finally, therapeutic nihilism has been associated with these chronically ill patients. ${ }^{23}$

Despite the comprehensive nature of the dataset, there are several limitations to consider in this analysis. First, we were unable to determine the cause and duration of kidney dysfunction and we did not have information regarding microalbuminuria or overt proteinuria. Second, we defined CKD on the basis of eGFR rather than on definite measurements of kidney function; however, direct measurements of GFR are rarely used in clinical practice. Third, hemodynamic changes that could occur from underlying cardiovascular disease or use of angiotensin antagonists that could 
potentially affect kidney function were not measured. Finally, measurements of eGFR were based on a single serum creatinine determination, which could have been influenced by unstable cardiac status. The strengths of this study are the large number of patients, the inclusion of several demographic, clinical, and operative factors for the patient, and a longer follow-up period than that of previous studies with a similar eGFR threshold. ${ }^{18,19}$

In conclusion, the preoperative measurement of kidney function, particularly eGFR, is a powerful and independent predictor of overall mortality and cardiovascular events in patients undergoing CABG. These results lead us to recommend the incorporation of preoperative eGFR into the risk assessments of perioperative and long-term outcomes after CABG.

\section{References}

1. Drey N, Roderick P, Mullee M, Rogerson M. A population-based study of the incidence and outcomes of diagnosed chronic kidney disease. Am J Kidney Dis. 2003;42:677-84.

2. Coresh J, Astor BC, Greene T, Eknoyan G, Levey AS. Prevalence of chronic kidney disease and decreased renal function in the adult US population: third national health and nutrition examination survey. Am J Kidney Dis. 2003;41:1-12.

3. Amann K, Tyralla K, Gross ML, Eifert T, Adamczak M, Ritz E. Special characteristics of atherosclerosis in chronic renal failure. Clin Nephrol. 2003;60:S13-21.

4. Mangano CM, Diamondstone LS, Ramsay JG, Aggarwal A, Herskowitz A, Mangano DT. Renal dysfunction after myocardial revascularization: risk factors, adverse outcomes, and hospital resource utilization. The Multicenter Study of Perioperative Ischemia Research Group. Ann Intern Med. 1998;128:194-203.

5. Liu JY, Birkmeyer NJ, Sanders JH, Morton JR, Henriques HF, Lahey SJ, et al. Risks of morbidity and mortality in dialysis patients undergoing coronary artery bypass surgery. Circulation. 2000;102:2973-7.

6. Anderson RJ, O'brien M, MaWhinney S, VillaNueva CB, Moritz TE, Sethi GK, et al. Renal failure predisposes patients to adverse outcome after coronary artery bypass surgery. VA Cooperative Study \#5. Kidney Int. 1999;55:1057-62.

7. O'Connor GT, Plume SK, Olmstead EM, Coffin LH, Martin JR. Multivariate prediction of in-hospital mortality associated with coronary artery bypass graft surgery. Circulation. 1992;85:2110-8.

8. Shroyer AL, Grover FL, Edwards FH. 1995 Coronary artery bypass risk model: The Society of Thoracic Surgeons Adult Cardiac National Database. Ann Thorac Surg. 1998;65:879-84.

9. Cooper WA, O'Brien SM, Thourani VH, Guyton RA, Bridges CR, Szczech LA, et al. Impact of renal dysfunction on outcomes of coronary artery bypass surgery: results from The Society of Thoracic Surgeons National Adult Cardiac Database. Circulation. 2006;113: 1063-70.

10. Hemmelgarn BR, Southern D, Culleton BF, Mitchell LB, Knudtson ML, Ghali WA, for the Alberta Provincial Project for Outcomes Assessment in Coronary Heart Disease (APPROACH) Investigators. Survival after coronary revascularization among patients with kidney disease. Circulation. 2004;110:1890-5.

11. Simmons PI, Anderson RJ. Increased serum creatinine: a marker for adverse outcome before and after cardiac surgery. Crit Care Med. 2002;30:1664-5.

12. Lok CE, Austin PC, Wang H, Tu JV. Impact of renal insufficiency on short- and long-term outcomes after cardiac surgery. Am Heart J. 2004:148:430-8.

13. Holzmann MJ, Ahnve S, Hammar N, Jorgensen L, Klerdal K, Pehrsson $\mathrm{K}$, et al. Creatinine clearance and risk of early mortality in patients undergoing coronary artery bypass grafting. $J$ Thorac Cardiovasc Surg. 2005;130:746-52.

14. Levey AS, Coresh J, Balk E, Kausz AT, Levin A, Steffes MW, et al; National Kidney Foundation. National Kidney Foundation practice guidelines for chronic kidney disease: evaluation, classification, and stratification. Ann Intern Med. 2003;139:137-47.

15. Brosius FC 3rd, Hostetter TH, Kelepouris E, Mitsnefes MM, Moe SM, Moore MA, et al. American Heart Association Kidney and Cardiovascular Disease Council; Council on High Blood Pressure Research; Council on Cardiovascular Disease in the Young; Council on Epidemiology and Prevention; Quality of Care and Outcomes Research Interdisciplinary Working Group. Detection of chronic kidney disease in patients with or at increased risk of cardiovascular disease: a science advisory from the American Heart Association Kidney and Cardiovascular Disease Council; the Councils on High Blood Pressure Research, Cardiovascular Disease in the Young, and Epidemiology and Prevention; and the Quality of Care and Outcomes Research Interdisciplinary Working Group: developed in collaboration with the National Kidney Foundation. Circulation. 2006;114:1083-7.

16. National Kidney Foundation: K/DOQI Clinical Practice Guidelines for Chronic Kidney Disease: evaluation, classification, and stratification: Am J Kidney Dis. 2002;39(Suppl 1):S1-266.

17. van de Wal RM, van Brussel BL, Voors AA, Smilde TD, Kelder JC, van Swieten HA, et al. Mild preoperative renal dysfunction as a predictor of long-term clinical outcome after coronary bypass surgery. J Thorac Cardiovasc Surg. 2005;129:330-5.

18. Hillis GS, Croal BL, Buchan KG, El-Shafei H, Gibson G, Jeffrey RR, et al. Renal function and outcome from coronary artery bypass grafting: impact on mortality after a 2.3-year follow-up. Circulation. 2006; 113:1056-62.

19. Zakeri R, Freemantle N, Barnett V, Lipkin GW, Bonser RS, Graham TR, et al. Relation between mild renal dysfunction and outcomes after coronary artery bypass grafting. Circulation. 2005;112:270-5.

20. Go AS, Chertow GM, Fan D, McCulloch CE, Hsu C. Chronic kidney disease and the risks of death, cardiovascular events, and hospitalization. N Engl J Med. 2004;351:1296-305.

21. Coresh J, Astor B, Sarnak M. Evidence for increased cardiovascular disease risk in patients with chronic kidney disease. Curr Opin Nephrol Hypertens. 2004;13:73-81.

22. Weiner DE, Tighiouart H, Amin MG, Stark PC, MacLeod B, Griffith JL, et al. Chronic kidney disease as a risk factor for cardiovascular disease and all-cause mortality: a pooled analysis of community-based studies. J Am Soc Nephrol. 2004;15:1307-15.

23. McCullough PA. Why is chronic kidney disease the "spoiler" for cardiovascular outcomes? J Am Coll Cardiol. 2003;41:725-8.

24. Schrier RW. Role of diminished renal function in cardiovascular mortality: marker or pathogenetic factor? J Am Coll Cardiol. 2006; 47:1-8.

25. Muntner P, Hamm LL, Kusek JW, Chen J, Whelton PK, He J. The prevalence of non-traditional risk factors for coronary heart disease in patients with chronic kidney disease. Ann Intern Med. 2004;140:9-17.

26. Shlipak MG, Fried LF, Crump C, Bleyer AJ, Manolio TA, Tracy RP, et al. Elevations of inflammatory and procoagulant biomarkers in elderly persons with renal insufficiency. Circulation. 2003;107:87-92.

27. London GM, Guerin AP, Marchais SJ, Metivier F, Pannier B, Adda H. Arterial media calcification in end-stage renal disease: impact on all-cause and cardiovascular mortality. Nephrol Dial Transplant. 2003;18:1731-40

28. Raggi P, Boulay A, Chasan-Taber S, Amin N, Dillon M, Burke SK, et al. Cardiac calcification in adult hemodialysis patients: a link between end-stage renal disease and cardiovascular disease? J Am Coll Cardiol. 2002;39:695-701.

29. Levin A, Thompson CR, Ethier J, Carlisle EJ, Tobe S, Mendelssohn D, et al. Left ventricular mass index increase in early renal disease: impact of decline in hemoglobin. Am J Kidney Dis. 1999;34:125-34.

30. Ezekowitz J, McAlister FA, Humphries KH, Norris CM, Tonelli M, Ghali WA, et al. The association among renal insufficiency, pharmacotherapy, and outcomes in 6,427 patients with heart failure and coronary artery disease. J Am Coll Cardiol. 2004;44:1587-92. 